Comparing accuracy of knowledge of functional effects of schizophrenia and brain

$$
\text { injury }
$$

This study developed and validated the Brain Injury and Schizophrenia Awareness Scale (BISAS) to compare accuracy of knowledge of functional effects of schizophrenia and TBI. The BISAS displayed good internal consistency and evidence of construct validity. Overall, general community participants $(n=143)$ lacked understanding of the shared effects of these conditions, and attributed emotional and behavioural deficits to schizophrenia and cognitive deficits to TBI.

Keywords: Scale Development, Neurocognitive Disorder, Mental Health Literacy 


\section{Comparing accuracy of knowledge of functional effects of schizophrenia and brain}

\section{injury}

\section{Introduction}

Schizophrenia and traumatic brain injury (TBI) are two leading causes of chronic disability worldwide (World Health Organisation, 2010). Despite different aetiology, schizophrenia and TBI are both neurocognitive disorders in which brain pathology interacts with environmental and personal factors to influence functioning. Characteristic symptoms of schizophrenia that are similar to severe TBI include emotional and behavioural difficulties and cognitive impairments (Singh et al., 2010). However, lateralised sensory-perceptual and physical impairments are distinctly associated with TBI (Ponsford et al., 2012), whereas positive symptoms are a primary feature of schizophrenia but not TBI (Compton et al., 2007).

Health literacy research highlights that greater knowledge of neurological and psychiatric disorders influences social attitudes and behaviour (Furnham and Blythe, 2012; Hux et al., 2006; Reavley and Jorm, 2011). Rather than focusing on a single condition, some studies have compared knowledge and attitudes towards different health conditions (e.g., Melas et al., 2013; Scior et al., 2013). The ability to both accurately identify and distinguish symptoms is likely to reduce generalisations made about people with disability and increase public awareness and support. For example, positive symptoms of schizophrenia such as hallucinations and delusions are more recognised by the public than negative symptoms and cognitive effects (Lauber et al., 2005). The public typically overgeneralises the effects of TBI (Ono et al., 2011), and views TBI as akin to mental illness (Swift and Wilson, 2001).

Existing studies of public knowledge and attitudes about schizophrenia and TBI (e.g., Compton et al., 2007; Hux et al., 2006) have focused on broader knowledge of each condition (e.g., prevention, aetiology, onset, symptoms), rather than the everyday effects. Current knowledge scales either contain few items assessing functional effects or tap symptoms in 
specific domains, such as positive symptoms for schizophrenia (Compton et al., 2007) and memory problems for TBI (Hux et al., 2006; Swift and Wilson, 2001).

To advance understanding of mental health literacy on two prevalent neurocognitive disorders, this study aimed to develop and validate the Brain Injury and Schizophrenia Awareness Scale (BISAS) and compare accuracy of knowledge of the functional effects of schizophrenia and TBI.

\section{Method}

\subsection{Development of the BISAS}

A review on the functional effects of TBI and schizophrenia led to development of a 60 item multiple-choice measure. Items related to lateralised sensory-perceptual and physical effects of TBI, positive symptoms of schizophrenia, shared cognitive and emotional and behavioural effects, and effects rarely apparent for either condition. The items were piloted by five experts on schizophrenia and brain injury whose qualifications spanned neuropsychology, clinical psychology, occupational therapy and consumer advocacy. The expert feedback led to removal of 15 items and development of two new items. The piloted 47-item version of the BISAS consisted of four response choices and subscales: a) common to TBI only (11 items), b) common to schizophrenia only (10 items), c) common to both TBI and schizophrenia (16 items), and d) rarely experienced in either schizophrenia or TBI (10 items). 'Common' was defined as effects that many people (i.e., at least 25\%) living in the community with the condition are likely to experience. Higher total BISAS scores represented greater accuracy of knowledge.

\subsection{Sampling}

A sample of 175 participants was recruited from the general community through the researchers' social networks. Participants were aged 18 to 74 years $(M=37.52, S D=14.93)$ 
and $61 \%$ were female. Participants in a professional sample $(n=40)$ recruited from mental health and disability organisations were predominantly female (88\%) and aged 22 to 66 years $(M=38.12, S D=12.09)$.

\subsection{Other measures}

The Head Injury Knowledge Scale (HIKS; Ono et al., 2011) measures misconceptions regarding effects of TBI using 14 true/false response options across two scales; overgeneralisation (8 items) and minimisation (6 items). Higher scores reflect greater misconceptions.

The Knowledge about Schizophrenia Test (KAST; Compton et al., 2007) is an 18-item multiple-choice test that assesses knowledge of schizophrenia. Higher scores (0-18) indicate greater accuracy of knowledge.

\subsection{Procedure}

Following university ethical clearance, surveys were distributed to general community participants via Lime Survey (V1.9) or hardcopy form. Participants completed a brief demographic survey. Recruitment of the professional sample was facilitated by directors of community mental health and disability organisations who emailed the survey link to staff.

\section{Results}

\subsection{Item analysis}

An item analysis was conducted on the 47-item BISAS using a random general community subsample $(n=30)$. Item retention was based on four properties; namely, discrimination index, difficulty index, Cronbach’s alpha and inter-item total correlations (see Carpenter et al., 2009). After removal of 16 items the 31-item BISAS (see Appendix) had good internal consistency for the total scale ( $\alpha=0.81$ ), and alpha was satisfactory for the four 
subscales $($ TBI $[9$ items $]=0.66$, Schizophrenia $[6$ items $]=0.76$, Shared effects $[12$ items $]=$ 0.75; Rarely experienced [4 items $]=0.58)$.

\subsection{Construct Validity}

Convergent validity of the BISAS ( $n=143$ ) was generally supported by the pattern of significant correlations with the HIKS and KAST (see Table 1). Discriminant validity was also indicated by the non-significant correlations between measures assessing different constructs (e.g., HIKS and BISAS Schizophrenia subscale, KAST and BISAS TBI subscale).

The professional sample $(n=40)$ was matched with a subsample of general community participants $(n=40)$ on age, gender, and education. Professionals demonstrated greater overall accuracy on the BISAS $(M=22.78, S D=3.4)$ compared to general community participants $(M=19.40, S D=5.1 ; t=3.50, p=0.001$, Cohen's $d=0.78)$. At a subscale level, professionals were significantly more accurate in identifying shared effects than the general community sample $(P<0.001, d=0.88)$. There were no significant between-group differences on the TBI, schizophrenia and rarely experienced subscales $(P>0.013)$.

\subsection{Rate and nature of misconceptions}

Participants were more likely to correctly endorse items related to distinct effects of schizophrenia (73.8\%) than TBI $\left(60.2 \% ; \chi^{2}=41.36, P<0.001\right)$, and were more accurate regarding distinct effects of schizophrenia (73.8\%) than shared effects $\left(55.9 \%, \chi^{2}=76.36\right.$, $P<0.001)$. They were also more likely to identify distinct effects of TBI $(60.2 \%)$ than shared effects $\left(55.9 \%, \chi^{2}=5.33, P=0.021\right)$. The most common misconceptions reflected the tendency to attribute emotional and behavioural deficits to schizophrenia and cognitive deficits to TBI (see Appendix). 


\section{Discussion}

The piloting and item analysis of the BISAS produced a 31-item scale with good overall internal consistency. The pattern of significant associations between the BISAS and the KAST and HIKS generally supported the construct validity of the BISAS, although the small to medium coefficients suggest differences in the knowledge domains assessed by these measures. Professionals working in the mental health and disability field were significantly more accurate overall in identifying the effects of schizophrenia and TBI than general community participants, which was mainly due to greater recognition of the shared effects of these conditions.

Response patterns indicated a tendency for general community participants to attribute emotional and behavioural effects mainly to schizophrenia and cognitive effects mainly to TBI. Previous mental health literacy research found that emotional and behavioural problems were readily associated with schizophrenia and that the prevalence and severity of these issues were overestimated (Lauber et al., 2005). Further, Ono et al. (2011) found that misconceptions regarding TBI were less common for cognitive effects, whereas emotional and behavioural changes were typically either minimised or overgeneralised.

A main limitation of this study relates to the convenience sample which contained more females (61\%) than males and was relatively well educated ( $M=13.5$ years). It is recommended that the influence of socio-cultural factors (e.g., ethnicity and socio-economic status) on knowledge accuracy be examined using population-based sampling. Further psychometric analysis is needed to validate the BISAS and improve reliability of the rarely experienced subscale.

Overall, these findings highlight that although the distinct effects of TBI and schizophrenia are largely well recognised, the shared effects are not well known unless people have relevant experience or contact with people with TBI and schizophrenia. Addressing gaps 
in knowledge is an important initial step towards improving mental health literacy concerning neurocognitive disorders. With further validation, the BISAS has potential to guide the focus of education initiatives for the lay public and community organisations (e.g., police, housing, employment). 


\section{References}

Carpenter, B. D., Balsis, S., Otilingam, P. G., Hanson, P. K., Gatz, M., 2009. The Alzheimer's disease knowledge scale: Development and psychometric properties. The Gerontologist 49, $236-247$.

Compton, M. T., Quintero, L., Esterberg, M. L., 2007. Assessing knowledge of schizophrenia: Development and psychometric properties of a brief, multiple-choice knowledge test for use across various samples. Psychiatry Research 151, 87-95.

Furnham, A., Blythe, C., 2012. Schizophrenia literacy: The effect of direct experience with the illness. Psychiatry Research 198, 18-23.

Hux, K., Schram, C. D., Goeken, T. 2006. Misconceptions about brain injury: A survey replication study. Brain Injury 20, 547-553.

Jorm, A. F., (2000). Mental health literacy: Public knowledge and beliefs about mental disorders. The British Journal of Psychiatry, 177, 396-401.

Lauber, C., Ajdacic-Gross, V., Fritschi, N., Stulz, N., Rössler, W., 2005. Mental health literacy in an educational elite-an online survey among university students. BMC Public Health 5, 44-52.

Melas, P. A., Tartani, E., Forsner, T., Edhborg, M., Forsell, Y., 2013. Mental health literacy about depression and schizophrenia among adolescents in Sweden. European Psychiatry 28, 404-411.

Ono, M., Ownsworth, T., Walters, B., 2011. Preliminary investigation of misconceptions and expectations of the effects of traumatic brain injury and symptom reporting. Brain Injury 25, 237-249. 
Ponsford, J., Sloan, S., Snow, P., 2012. Traumatic brain injury: Rehabilitation for everyday adaptive living, 2nd ed. Psychology Press, Hove, UK.

Reavley, N.J., Jorm, A.F., 2011. Stigmatizing attitudes towards people with mental disorders: Findings from an Australian national survey of mental health literacy and stigma. Australian and New Zealand Journal of Psychiatry 45, 1086-1093.

Scior, K., Potts, H. W., Furnham, A. F., 2013. Awareness of schizophrenia and intellectual disability and stigma across ethnic groups in the UK. Psychiatry Research 208, 125-130.

Singh, S. P., Singh, V., Kar, N., Chan, K., 2010. Efficacy of antidepressants in treating the negative symptoms of chronic schizophrenia: Meta-analysis. The British Journal of Psychiatry 197, 174-179.

Swift, T. L., Wilson, S. L., 2001. Misconceptions about brain injury among the general public and non-expert health professionals: An exploratory study. Brain Injury 15, 149-165.

World Health Organisation. (2010). Neurological disorders: Public health challenges. Retrieved from www.who.int/eu. 
Appendix: BISAS Items and Misconception Rate

\begin{tabular}{|c|c|c|}
\hline $\begin{array}{l}\text { Item } \\
\text { no. }\end{array}$ & BISAS items & $\begin{array}{l}\text { Misconception } \\
\text { rate (\%) }\end{array}$ \\
\hline 1 & $\begin{array}{l}\text { Experience a loss of vision for either the left or right side of space in } \\
\text { front of them }(T)\end{array}$ & 21 \\
\hline 2 & $\begin{array}{l}\text { Hear two or more voices conversing with one another that are distinct } \\
\text { from the person's own thoughts (S) }\end{array}$ & 17 \\
\hline 3 & Have a poor understanding of the effects of their condition (B) & 39 \\
\hline 4 & Become irritated easily when under stress (B) & 31 \\
\hline 5 & Have difficulty adjusting behaviour to suit the social situation (B) & 53 \\
\hline 6 & $\begin{array}{l}\text { Have difficulty recognising an object on a shelf with other objects that } \\
\text { look similar }(\mathrm{T})\end{array}$ & 34 \\
\hline 7 & $\begin{array}{l}\text { Miss or fail to notice objects on the left side, but not the right side of } \\
\text { their environment }(\mathrm{T})\end{array}$ & 34 \\
\hline 8 & Have difficulty identifying their own emotions (B) & 46 \\
\hline 9 & $\begin{array}{l}\text { Feel anxious or low in self-confidence when interacting with the general } \\
\text { public (B) }\end{array}$ & 41 \\
\hline 10 & $\begin{array}{l}\text { Have one side of the body that is stronger and more coordinated than the } \\
\text { other }(T)\end{array}$ & 36 \\
\hline 11 & Hear other people's voices coming from inside their own head (S) & 15 \\
\hline 12 & $\begin{array}{l}\text { Display a range of facial expressions that are appropriate to the situation } \\
\text { and topic of conversation (R) }\end{array}$ & 54 \\
\hline 13 & $\begin{array}{l}\text { Become so preoccupied by their own thoughts that they neglect their } \\
\text { personal hygiene (S) }\end{array}$ & 50 \\
\hline 14 & Express frustration verbally (B) & 41 \\
\hline 15 & $\begin{array}{l}\text { Have difficulty scanning the environment to find an object they are } \\
\text { looking for }(\mathrm{T})\end{array}$ & 47 \\
\hline 16 & Believe that other people are following and spying on them (S) & 13 \\
\hline 17 & $\begin{array}{l}\text { Have difficulty noticing when they have said or done something that } \\
\text { upsets another person (B) }\end{array}$ & 55 \\
\hline 18 & Be highly skilled in social interaction (R) & 22 \\
\hline 19 & Have difficulty getting motivated to carry out daily activities (B) & 40 \\
\hline 20 & Have difficulty starting conversations with other people (B) & 40 \\
\hline 21 & $\begin{array}{l}\text { Find it easier to describe something using words than pictures OR vice } \\
\text { versa }(\mathrm{T})\end{array}$ & 72 \\
\hline 22 & $\begin{array}{l}\text { Believe the news reader on the television is communicating a message } \\
\text { to them }(S)\end{array}$ & 27 \\
\hline 23 & Have difficulty reading or following a map (T) & 49 \\
\hline 24 & Have difficulty planning or initiating actions (B) & 53 \\
\hline 25 & Experience a loss of feeling down one side of the body $(\mathrm{T})$ & 27 \\
\hline 26 & Have difficulty anticipating the consequences of their own actions (B) & 46 \\
\hline 27 & $\begin{array}{l}\text { Have difficulty completing complex tasks that require planning, such as } \\
\text { grocery shopping or budgeting (B) }\end{array}$ & 43 \\
\hline 28 & Spend time carefully thinking through a decision before acting (R) & 46 \\
\hline 29 & Believe they are highly influential and have special gifts (S) & 35 \\
\hline 30 & Have difficulty naming familiar objects (T) & 39 \\
\hline 31 & Consistently complete tasks from start to finish (R) & 30 \\
\hline
\end{tabular}

$\mathrm{T}=\mathrm{TBI}, \mathrm{S}=$ schizophrenia, $\mathrm{B}$ = both TBI and schizophrenia, $\mathrm{R}$ = rarely experienced 